\title{
Aspects of remote asymmetric induction using allylstannanes
}

\author{
J. S. Carey, T. S. Coulter, D. J. Hallett, R. J. Maguire, A. H. McNeill, S. J. \\ Stanway, A. Teerawutgulrag, and E. J. Thomas* \\ Department of Chemistry, University of Manchester, Manchester, M13 9PL, U.K.
}

\begin{abstract}
Transmetallation of allylstannanes with heterosubstituents at the 4-, 5- and 6positions using tin(IV) halides generates allyltin trihalides which react with aldehydes to give homoallylic alcohols with excellent 1,5-, 1,6- and 1,7-asymmetric induction. Preliminary investigations indicate that imines prepared from butyl glyoxalate react with the allyltin trichloride prepared from 4- and 5-benzyloxypent-2-enyltributylstannanes with useful 1,5-asymmetric induction.
\end{abstract}

(E)-But-2-enyltributylstannane 1 reacts with aldehydes on heating to give anti-1-substituted 2-methylbut-3enols 3 via concerted processes involving cyclic, chair-like, transition states 5 (1). 1-Alkoxybut-2-enylstannanes 2 give 4-alkoxy-1,2-anti-3,4-cis-but-3-en-1-ols 4 showing that the 1-substituent in the stannane prefers to adopt the axial position in the transition state 6 since reaction via transition state 7 , in which the 1substituent is equatorial, would give rise to trans-alkenes, which are not observed (2). The (1R)- and (1S)-1alkoxybut-2-enylstannanes $\underline{8}$ and $\underline{11}$ therefore react with the $S i$ - and $R e$-faces of benzaldehyde to give the $(1 S, 2 S)$ - and $(1 R, 2 R)$-products 9 and $\underline{12}$, via transition states 10 and 13 , with excellent stereoselectivity (3).

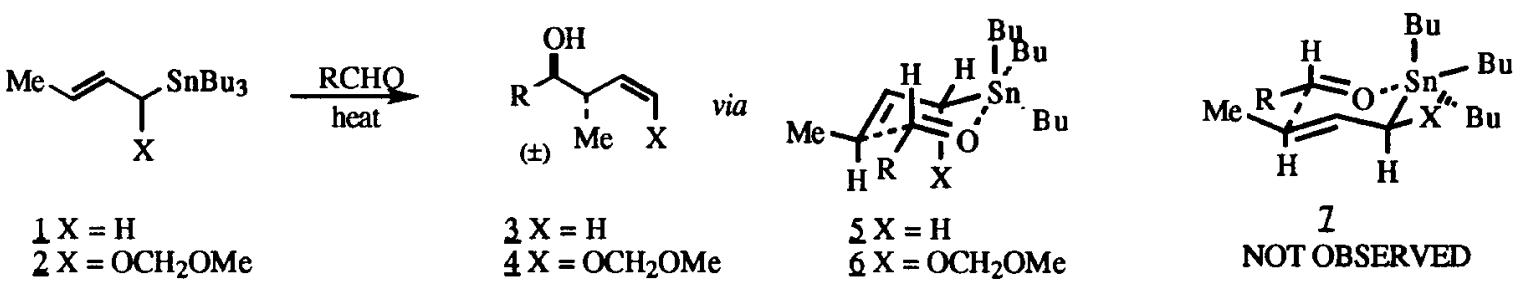

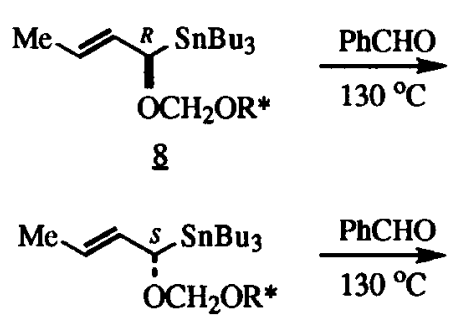

11<smiles>[M]C(/C=C\OCOc1ccccc1)C(O)c1ccccc1</smiles>

2<smiles>[M]C(/C=C\OCOCc1ccccc1)[C@H](O)c1ccccc1</smiles>

12 via

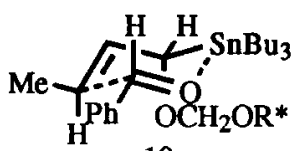

10

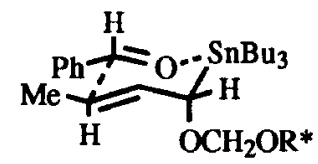

13

$\left(\mathrm{R}^{*}=\right.$ menthyl)

In the presence of boron trifluoride diethyl etherate, both $(E)$ - and $(Z)$-but-2-enylstannanes 14 react with aldehydes at $-78{ }^{\circ} \mathrm{C}$ to give predominantly syn-products 15 via the open-chain process 16 in which the rate acceleration is due to co-ordination of the aldehyde by the Lewis acid (4). Other Lewis acids effect transmetallation of allylstannanes to generate more reactive allylmetal species which then react with the aldehyde. For example, treatment of 3-phenylprop-2-enylstannane 17 with butyltin trichloride generates (1phenylprop-2-enyl)butyltin dichloride 18 which can be trapped with aldehydes to give 1-substituted (Z)-4phenylbut-3-en-1-ols 19, via the cyclic transition state 20 in which the 1-phenyl substituent is axial. On standing, 18 rearranges to its 3 -phenyl-isomer 21 which reacts with aldehydes to give anti-products 22 (5). 


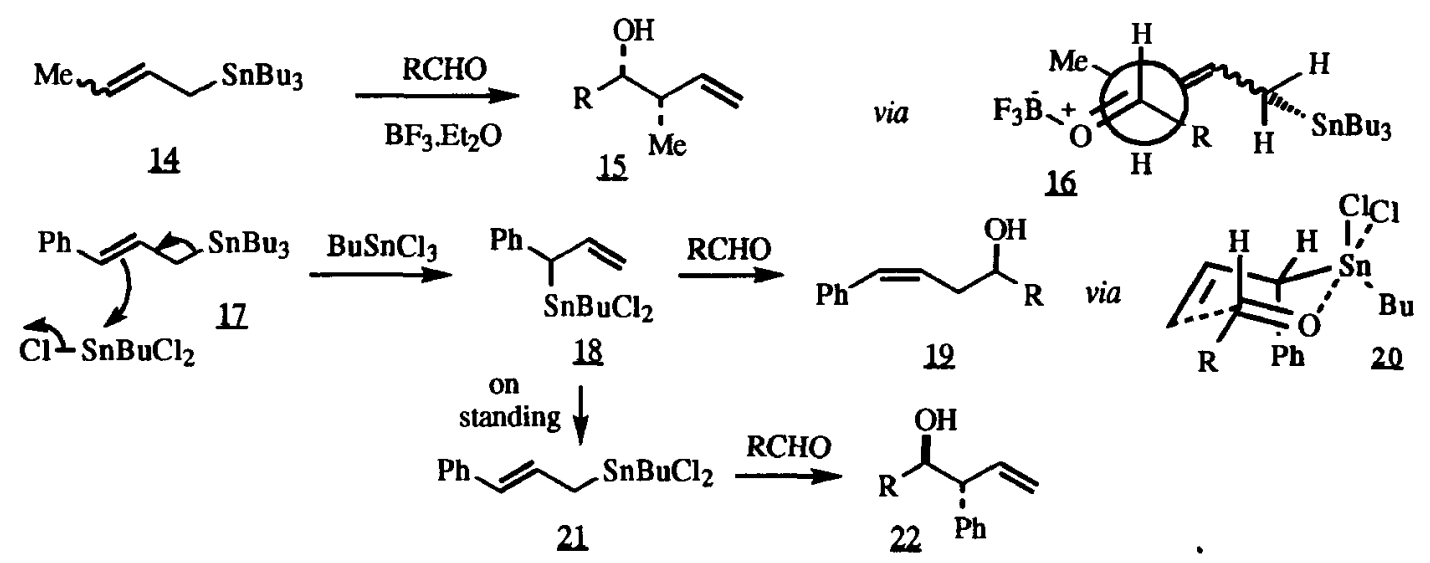

The 4-benzyloxypen-2-enylstannane $\underline{23}$ was found to exhibit only low diastereofacial selectivity in reactions with aldehydes at $150^{\circ} \mathrm{C}$ and in the presence of boron trifluoride diethyl etherate (6). However, treatment of the stannane $\underline{23}$ with tin(IV) chloride followed after 5-10 min. by the addition of an aldehyde gave rise to the formation of 1-substituted syn-5-benzyloxy-(3Z)-hex-3-en-1-ols 24 with excellent stereoselectivity (7).<smiles>CC(C)COC(C)C=CC[18CH]C(C)C</smiles>
23
1. $\mathrm{SnCl}_{4},-78^{\circ} \mathrm{C}, 5 \mathrm{~min}$

2. RCHO, $-78^{\circ} \mathrm{C}, 1 \mathrm{~h}$

$70-90 \%$<smiles>[R]C(O)CC=CC(C)OCc1ccccc1</smiles>

1,5-syn-isomer

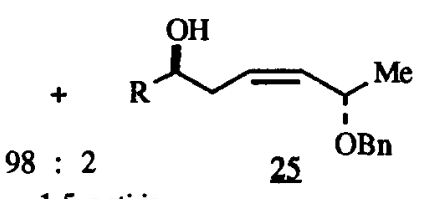

1,5 -anti-isomer

The selective formation of the 1,5-syn-isomer 24 is consistent with a stereoselective transmetallation of the stannane 23 to generate the allyltin trichloride 26 in which the electron deficient tin is co-ordinated to the benzyloxy substituent. This allyltin trichloride then reacts with the aldehyde via the cyclic, chair-like transition state 27 in which the group $\alpha$ to the tin is axial, $c f . \underline{6}$. This preference establishes the stereochemistry at the newly formed chiral centre relative to the chiral centre derived from the stannane and establishes the Z-geometry of the alkene (7). 1,5-syn-Products were also obtained with useful stereoselectivity from the 4-dibenzylamino and 4,5-disubstituted pent-2-enylstannanes 29 and $31(8,9)$.

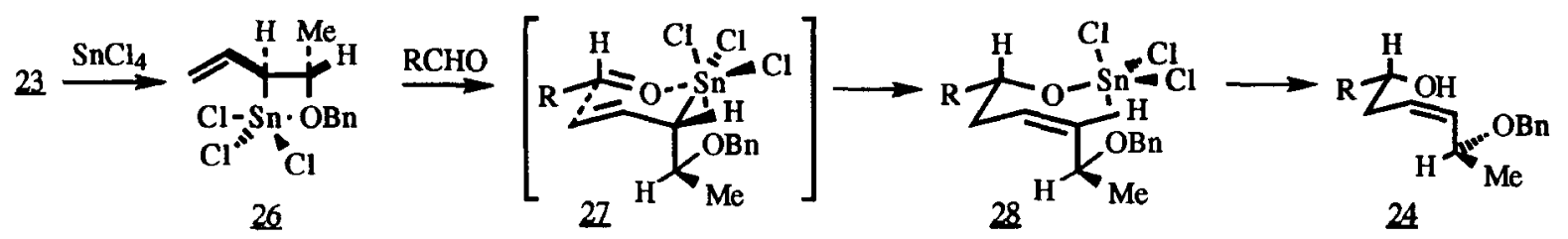<smiles>[R]C(O)C/C=C\C(C)NCCCCCCC(C)C</smiles><smiles>[M]OC(C=CCC(C)C)C(CO)O[R]</smiles>

The scope of remote stereochemical control using allylstannanes with heteroatom substituents was studied. Treatment of 5-alkoxy- and 5-alkylthio-4-methylpent-2-enylstannanes 33 , 34, and 37 with either tin(IV) chloride or tin(IV) bromide generated an intermediate which reacted with aldehydes with useful anti-1,5stereoselectivity (10-12). This stereoselectivity was observed for 5-substituted stannanes with benzyloxy, $p$ methoxybenzyloxy, methoxymethoxy, and 2-trimethylsilylethoxymethoxy substituents and similar, albeit slightly reduced, stereoselectivity was observed for the corresponding 5-hydroxy- and 5-tert-butyldimethylsilyloxystannanes (13). The geometry of the double-bond of the stannane, particularly in the case of the 2,4-dimethylpent-2-enylstannane 34 , was found to be unimportant. The stereoselectivity of these reactions is consistent with the stereoselective formation of an allyltin trihalide, e.g. 39 which reacts with aldehydes via the six-membered, cyclic, transition state 40 in which the group $\alpha$ to tin is axial and controls the facial selectivity of the reaction with the aldehyde. 
$\mathrm{Bu}_{3} \mathrm{Sn} \overbrace{\mathrm{R}^{2}}^{\mathrm{Me}^{2}} \mathrm{OR}^{1} \frac{1 . \mathrm{SnCl}_{4},-78^{\circ} \mathrm{C}}{2 . \mathrm{R}^{3} \mathrm{CHO},-78^{\circ} \mathrm{C}}$

$33 \mathrm{R}^{2}=\mathrm{H}$

$34 R^{2}=M e$

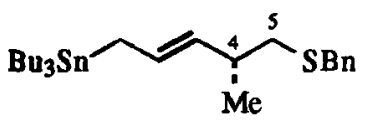

37<smiles>[R]CC([R4])CC([R4])CO[R]</smiles>

$35 R^{2}=H$

$36 R^{2}=M e$

via 33

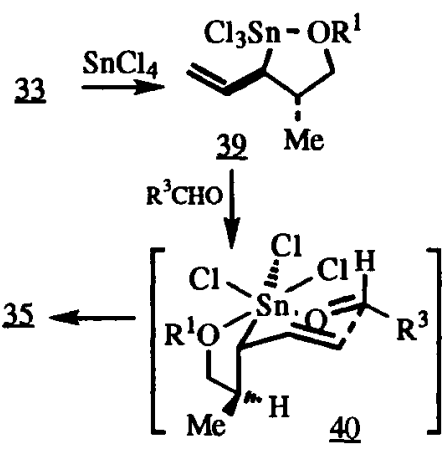

In contrast, 5-acyloxypent-2-enylstannanes 41 were found to give more of the anti-(E)-hex-3-en-1-ols 42 in reactions with aldehydes promoted by either tin(IV) bromide or chloride although the stereoselectivity was not high enough to be useful. Perhaps the allyltin trihalides 43 in which the carbonyl oxygen is co-ordinated to the tin are involved. These may then react with aldehydes via transition states 44 in which the group $\alpha$ to tin is equatorial (14).

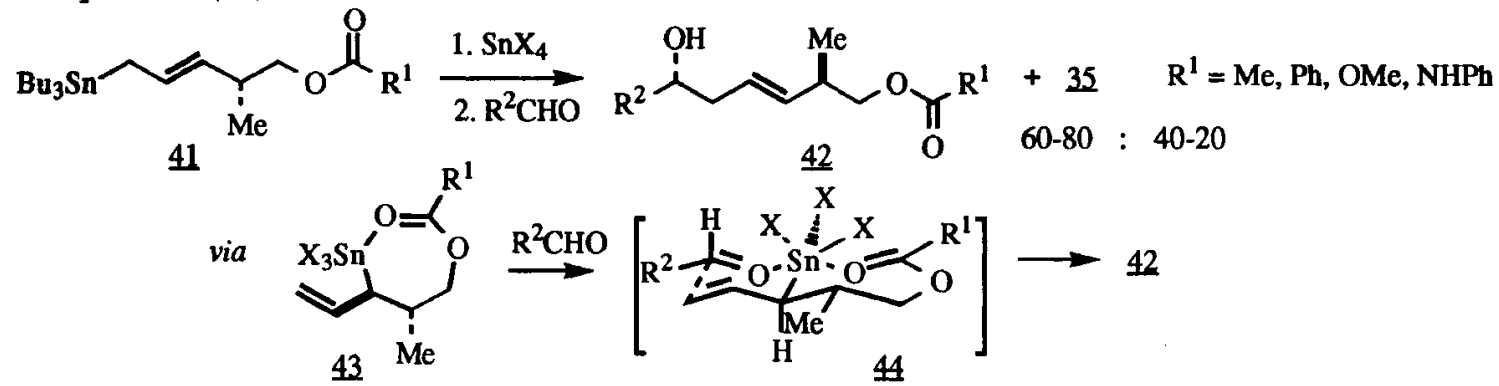

5-Hydroxy- and 5-methoxyhex-2-enyltributylstannanes $\underline{45}(\mathrm{R}=\mathrm{H}, \mathrm{Me})$ react with aldehydes after transmetallation with tin(IV) bromide to give the syn-1,6-products 46 ( $R=H, M e)$ with useful 1,6 asymmetric induction consistent with the participation of the allyltin tribromide 47 in which the vinyl and methyl groups are cis disposed about the five-membered ring (15). Lower stereoselectivities were obtained with bulkier groups on the oxygen and with tin(IV) chloride. 1,6-anti-Stereoselectivity was observed for the 5-methyl-6-hydroxyhex-2-enylstannane 48 and 1,7-syn-stereoselectivity for the 6-hydroxyhept-2enylstannane $51(16,17)$. In both cases the stereoselectivity is consistent with transmetallation of the allylstannane to generate an allyltin tribromide in which the electron deficient tin is co-ordinated by the oxygen to form a six-membered ring with both the vinyl and methyl substituents equatorial. Subsequent reaction with the aldehyde involves a chair-like transition state with the group $\alpha$ to tin axial.<smiles>[R]C(O)CC=CCCCC</smiles>

45<smiles>[Y4]C(CO)CC=CCCCCC</smiles>

$\underline{48}$<smiles>CC(C)CCC=CCCC(C)O</smiles>

51

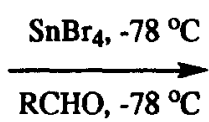

$70-80 \%$

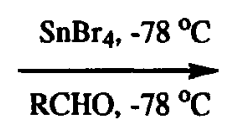

RCHO, $-78{ }^{\circ} \mathrm{C}$<smiles>[R]C(O)C/C=C\CC([M])CO</smiles>

1,6-anti : 1,6-syn $\geq 91: 9$<smiles></smiles>

47<smiles></smiles>

50<smiles>[Y4][C@@H]1CC[C@H](C=C)O[C@@H]1Br</smiles>

53

Preliminary investigations have been carried out into remote asymmetric induction in reactions between imines and allylstannanes. Both boron trifluoride diethyl etherate and titanium(IV) chloride catalyse reactions 
between imines and allylstannanes (18), but for the remote asymmetric induction it was necessary to develop conditions for reactions between allyltin trihalides and imines. Simple imines did not react with prop-2enyltin trichloride 55 at $-78{ }^{\circ} \mathrm{C}$. However, the imine 54 prepared from butyl glyoxalate and $(R)-1$ phenylethylamine reacted with the prop-2-enyltin trichloride to give the $2-(R)$-pentenoate 56 with excellent stereoselectivity. This selectivity is the opposite from that observed using allyl-9BBN, and establishes the intrinsic facial preference of the imine 54 in reactions with allyltin trichlorides (19).<smiles>C=CC[Se]CCCCC(C)(C)c1ccccc1</smiles>

54

55

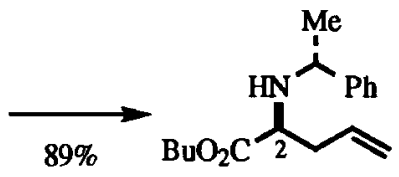

$\underline{56}$<smiles>[M]C(N[C@@H](CC=C)C(=O)O)C(=O)OCc1ccccc1</smiles>

$93: 7$
57

The intermediate generated by treatment of the (4S)-4-benzyloxypent-2-enylstannane 23 with tin(IV) chloride reacted with both the $(R)$ - and $(S)$-imines 54 and ent- 54 with excellent stereoselectivity in favour of the 1,5 anti-products $\underline{\mathbf{5 1}}$ and $\mathbf{5 9}$ although the selectivity was slightly better when this anti-selectivity was matched with the intrinsic selectivity of the imine. With the 5-benzyloxy-4-methylpent-2-enylstannane 33 ( $R^{1}=\mathrm{Bn}$; $\mathrm{R}^{2}=\mathrm{H}$ ), this matching and mis-matching were more apparent and useful selectivity was only obtained when the 1,5-syn-preference of the stannane was matched with the intrinsic bias of the imine (19).

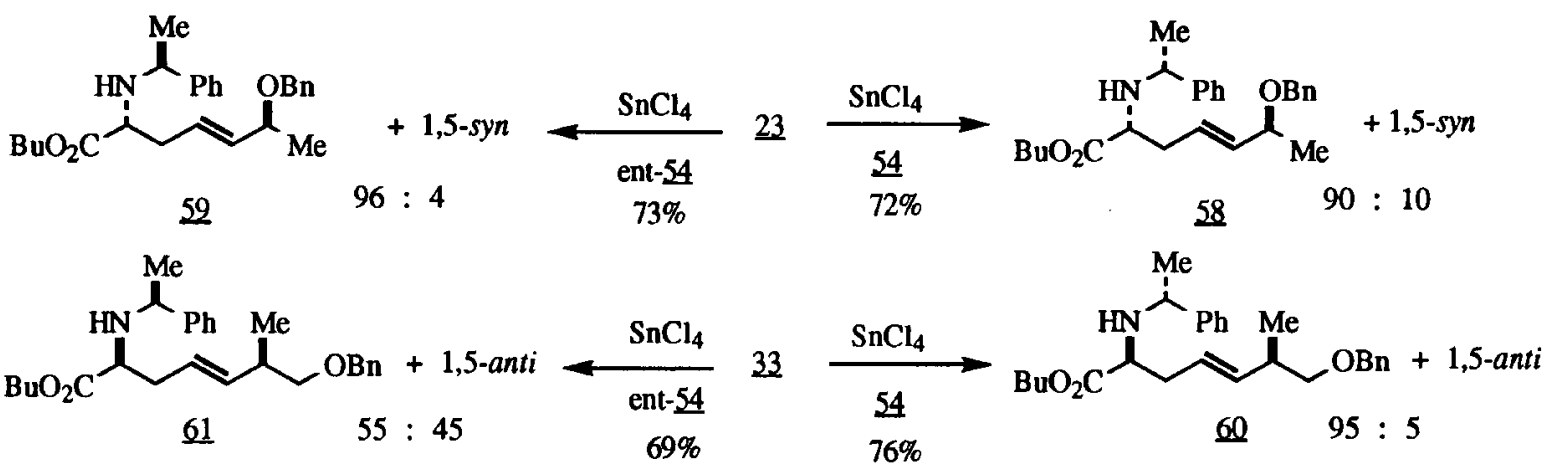

The selective formation of $(E)$-alkenes in reactions of the alkoxyallylstannanes 23 and 33 with imines contrasts with the formation of $(Z)$-alkenes in reactions with aldehydes and may be indicative of open-chain transition states, although both open-chain and cyclic processes can be devised which are consistent with both the imine facial selectivity and the 1,5-stereoselectivity. Present work is concerned with the application of this chemistry to the synthesis of complex natural products and the use of other allylmetal reagents (20).

\section{REFERENCES}

1. C. Servens and M. Pereyre, J. Organomet. Chem., 35, C20 (1972).

2. A. J. Pratt and E. J. Thomas, J. Chem. Soc., Perkin Trans I, 1521 (1989).

3. V. J. Jephcote, A. J. Pratt and E. J. Thomas, J. Chem. Soc., Perkin Trans l, 1529 (1989).

4. Y. Yamamoto, H. Yatagai, Y. Ishihara, N. Maeda and K. Maruyama, Tetrahedron, 40, 2239 (1984).

5. H. Miyake and K. Yamamura, Chem. Lett., 1473 (1993).

6. S. V. Mortlock and E. J. Thomas, Tetrahedron Lett., 29, 2479 (1988).

7. A. H. McNeill and E. J. Thomas, Synthesis, 233 (1994).

8. S. J. Stanway and E. J. Thomas, J. Chem. Soc., Chem. Commun., 285 (1994).

9. R. J. Maguire and E. J. Thomas, unpublished observation.

10. J. S. Carey and E. J. Thomas, Synlett, 585 (1992).

11. A. Teerawutgulrag and E. J. Thomas, J. Chem. Soc., Perkin Trans. I, 2863 (1993).

12. S. J. Stanway and E. J. Thomas, unpublished observations.

13. J. S. Carey, T. S. Coulter and E. J. Thomas, Tetrahedron Lett., 34, 3933 (1993).

14. T. S. Coulter, A. Teerawutgulrag and E. J. Thomas, unpublished observations.

15. J. S. Carey and E. J. Thomas, Tetrahedron Lett., 34, 3935 (1993).

16. S. J. Stanway and E. J. Thomas, unpublished observations.

17. J. S. Carey and E. J. Thomas, J. Chem. Soc., Chem. Commun., 283 (1994).

18. G. E. Keck and E. J. Enholm, J. Org. Chem., 50, 146 (1985); Y. Yamamoto, T. Komatsu, and K. Maruyama, J. Org. Chem., 50, 3115 (1985).

19. D. J. Hallett and E. J. Thomas, unpublished observations.

20. C. T. Brain, G. W. Bradley, and E. J. Thomas, unpublished observations. 